\title{
Improving housing and neighborhoods for the vulnerable: older people, small households, urban design, and planning
}

\author{
Ann Forsyth $^{1} \cdot$ Jennifer Molinsky ${ }^{2} \cdot$ Har Ye Kan $^{3}$
}

Published online: 18 January 2019

(c) The Author(s) 2019

\begin{abstract}
The number of older people who need help with daily tasks will increase during the next century. Currently preferences and policies aim to help older people to stay in their existing homes, to age in place, even as they become less able to care for themselves and, increasingly, live alone. However, the majority of homes in the U.S. and many other countries are not designed to support advanced old age or are not located to easily provide support and services. The paper explores the needs of older people experiencing frailty. It examines the existing range of innovations to make neighbourhoods and homes more supportive, physically, socially, and in terms of services. These include: enriching neighbourhoods, providing collective services, building all-age neighbourhoods, creating purpose-built supportive housing, developing smallscale intergenerational models, and engaging mobility, delivery, and communications innovations. Some will allow people to remain in their current dwelling but others focus on people remaining in a local community. Few are widely available at present. Urban designers can more fully engage with the multiple challenges of those who have physical, sensory, and cognitive impairments and living in solo households by becoming champions for a more comprehensive set of public realm improvements and linkages.
\end{abstract}

Keywords Older people $\cdot$ Frail $\cdot$ Housing $\cdot$ Neighbourhood $\cdot$ Health $\cdot$ Single

\section{Planning and design for the vulnerable}

This paper lays out a conundrum. In many locations around the world older people want to stay in their current homes, to "age in place," even as challenges of self-care, mobility, and household management increase with age (Roy et al. 2018). Government policies support aging in place as an alternative to more expensive institutional care, such as in nursing homes. However, very often older adults' current homes are not designed to support advanced old age, nor are they located to easily provide support and services. Increasingly older people are living alone, further complicating the

Ann Forsyth

aforsyth@gsd.harvard.edu

Jennifer Molinsky

jennifer_molinsky@harvard.edu

1 Department of Urban Planning and Design, Harvard GSD, 48 Quincy Street, Cambridge, MA 02138, USA

2 Joint Center for Housing Studies, 1 Bow Street, 4th Floor, Cambridge, MA 02138, USA

3 International Studies Program, Hope College, 126 East 10th Street, Holland, MI 49423, USA tasks of care and support. This paper sets out the scope of the coming challenge, outlines the range of existing innovations, and proposes a set of roles for those in urban design (broadly defined).

Growth in older populations, particularly among those who experience physical and cognitive impairments and who live alone, will challenge urban planners and urban designers to create homes and neighborhoods that support older people, physically, socially, and in terms of services. The paper focuses on two central questions related to this situation: What are the specific challenges that cities and regions will have to face due to this increase in vulnerable, often single-person households? What urban design and planning strategies can better adapt places to this new reality-both already tested and plausible?

This paper proposes that there are many existing and nascent innovations that can support older adults and help them maintain independence into older ages. These include innovations in housing design but also those that connect older people who live independently with the services they need to manage age-related impairments. Approaches include: (a) enriching neighborhood infrastructure and services in a participatory, collaborative, and multifaceted way; (b) adding formal and 
volunteer-based collectively delivered services to existing neighborhoods to allow people to age-in-place; (c) creating a range of housing and service options for older people in new large-scale developments or all-age neighborhoods; (d) providing more domestic-scaled models of purpose-built supportive housing; (e) mixing older people with others in finegrained, small-scale intergenerational housing options allowing informal care; (f) expanding mobility through low-tech and high-tech improvements; and ( $\mathrm{g}$ ) building on delivery and communications innovations to connect older people to goods, services, and networks.

These are issues for urban design as a field, and for the area of urban planning that intersects with it, because the physical environment plays a central role in the lives of older people at a scale beyond the individual home which has been the main focus of so much work in this area. While the home is certainly important, it is also a hub from which older people go out into their surroundings to engage with others, access services, interact with the natural world, and undertake other activities. It is the place to which services, communications, and products are delivered by others who also engage with those surroundings. Many innovations cluster older people in purpose-built housing for both social interaction and efficient servicing; the physical design of their local context is key to their success. Others upgrade existing neighborhoods so they can support older adults' activities and engagement for longer. All innovations currently in use embrace some interaction among physical place, social and economic arrangements (including services and activities), and inhabitants. This kind of interaction is arguably at the core of the best urban designs-as physical form alone is rarely enough to make a great place (Carmona et al. 2003; Lang 2005).

This paper first lays out a framework connecting the work of urban design to the needs of the more vulnerable part of the aging population - at the level of the person, the physical environment, and the social context. It then examines the challenges of supporting growing populations of older adults, many of them experiencing multiple physical and cognitive problems and living alone in homes and neighborhoods that do not support their needs. We then turn to the role of solutions that can be championed and implemented by designers and planners to support this growing segment of society. Many are currently in existence but have not been comprehensively implemented. The reasons for this vary around the world but wider implementation would benefit from champions within the fields of urban design and planning.

\section{Aging and urban design}

Aging has not always been central to an urban design agenda. Even the field of housing has not always put aging front and center, though there are vibrant debates and even specialized journals, such as the long-running Journal of Housing for the Elderly. Urban design can be conceptualized more narrowly as something like big architecture or architecture with a sense of context, or more broadly as the form of the city defined by designers, planners, regulators, developers, and more (Lang 2005; Krieger 2006). Both ends of this spectrum have a role in creating environments for aging, though the broader views intersect in more dimensions. A focus on the urban design dimensions of aging can help housers, who often look at the scale of the building or wider policy issues, to identify the neighborhood-level implications of aging. It can help urban designers and planners understand the potential of their work to enhance life in later years.

Urban design can be informed by the field of environmental gerontology which has developed several theories about how older people are supported, or not, by places. The most influential is the ecological theory of aging (ETA) where people's behavior depends on individual competence, stresses placed by the environment, and the interaction between the person and environment (Lawton and Nahemow 1973; Lawton 1980). Several other theories build from this theory, often via critique, adding a sense of the older person's agency (choices, compensations, skills optimization), and the dimension of change over time (Lien et al. 2015; Baltes and Baltes 1990; Diaz Moore 2014). A second body of theory, on aging well, active aging, or a positive view of aging, focuses on the social environment and the capacity of older people to maintain capacities, engage with others, and maintain independence over time (WHO 2002; Wahl et al. 2012; Rowe and Kahn 1998). This has potential to be extended to the physical environment as well.

These theories see older people as quite varied, from the robust to those who have multiple disabilities. In the areas of urban design and urban planning, however, much of the attention has been placed on providing environments for those who still have many capacities intact and need environments that are challenging enough to maintain these capacities. The exception is universal design, and particularly wheelchair access, where there has been a great deal of activism from a wide range of age groups. Universal design is limited, however, in its helpfulness to frail older adults who may experience multiple social, service, and physical barriers to leaving the home, from air quality to traffic safety problems. The broader "inclusive" design has not yet been widely enough adopted (Institute for Human Centered Design 2018).

Part of the reason for this focus on active older adults may be that those with multiple disabilities are less visible in the wider world, often retreating to the safety and predictability of their homes. However, even those who spend most of their time at home interact with the wider world through services, deliveries, communications, and through the views they see 
from their windows. With better urban environments linked to services and technologies, the period in which older people can get out and about in the wider physical world likely could be lengthened. Table 1 explains some of the ways that designers and planners can create more supportive environments. While some of these seem simple, they are often overlooked.

Ideally, environments provide basic needs for people across age groups. At the level of the person, they both support and provide appropriate challenge for a range of abilities. Physically they limit exposures to harmful chemicals and injuries, provide access to resources needed to live a healthy life (such as healthcare), and create supports for doing healthful things such as being physically active, eating healthy food, or enjoying the benefits of nature in terms of well-being (Masotti et al. 2006; Clark and Nieuwenhuijsen 2009; Hunter et al. 2011, p. 356; Forsyth et al. 2017; Rowe et al. 2016). Socially, supportive environments provide affordable housing options and opportunities for interacting with others.

\section{Challenges of an aging population}

\section{Growing aging population}

Over the last century life expectancy has increased, mostly due to improvement in mortality among infants and children. In 1900, life expectancy at birth in the United States was 52 years for men and 58 for women; by 2015 it was 81 for men and 86 for females, a rise of about three decades over the span of a century. Globally in 2015 life expectancies were 69 and 74 years for men and women (WHO n.d.). For people who have reached older ages, life expectancy has also improved but by fewer years: in 1900 65-year-olds in the United States could expect to live 11 more years for males and 12 for females; by 2015 these were projected to be 17 years for men and 20 for women (Bell and Miller n.d.).
With this increase in life expectancy has come a substantial increase in the share of the population that is older. In the US, the share of the population aged 65 and over rose from $4.1 \%$ in 1900 (around 3 million) to $12.4 \%$ in 2000 (nearly 35 million), and is projected to reach $20 \%$ in 2030 (almost 73 million) (West et al. 2014). Some other countries that have less immigration bringing younger people to the country will have populations with still higher shares of older adults.

\section{Smaller households}

With population shifts as well as a decrease in some countries in traditional multigenerational households (in which a parent might live in the home of a child, for example), the number of older households will also grow. In the U.S., 57\% of households headed by those 65 and over are expected to be single-person units by 2035 (JCHS 2016, p. 6). Already, just under half the women in the U.S. aged 85-94 live alone (Fig. 1). This pattern appears worldwide (Prioux et al. 2010, p. 385). Of course married households are also small and have challenges, but this will be exacerbated by the increase of solo households.

There are many reasons for this rise in single-person households. Lower marriage rates and higher divorce rates mean fewer people enter older age as married couples (JCHS 2016, p. 6; Wang and Parker 2014). Women's longer life spans, combined with a tendency to marry older men, mean that on average even those women who do marry and remain so will be widows in their final years.

Solo living may increase further as fewer older adults reside with their children in the future. In most parts of the world, families are having fewer children, meaning in the future there will be fewer options for living with, or receiving care from, children later in life. There are many reasons for lower birth rates and childlessness but generally higher education, later marriage, divorce, workforce participation, and the like have contributed. In the OECD, rates of childlessness increased from the mid-1990s to 2010, with only four countries showing a decrease. By 2010, Austria,

Table 1 Urban design and planning's role providing support for frail older people in small households

\begin{tabular}{lc}
\hline Person-environment issues & Urban design and planning's role \\
\hline $\begin{array}{l}\text { Person: } \\
\text { Agency, experience, behavior, belonging, perceptions; mobility, sen- } \\
\text { sory, and mental conditions }\end{array}$ & $\begin{array}{c}\text { Create supportive local environments for different levels of ability, } \\
\text { minimizing stressors and maximizing supports for people at every } \\
\text { stage of aging as people change over time }\end{array}$ \\
$\begin{array}{l}\text { Physical environment features } \\
\begin{array}{l}\text { Exposures, accessibility/mobility, urban form supports, destinations \& } \\
\text { services }\end{array}\end{array}$ & $\begin{array}{r}\text { Using the lens of aging, create an environment that is safe (from traffic, } \\
\text { pollunts, perceived and actual crime), meaningful, service-rich, and }\end{array}$ \\
$\begin{array}{l}\text { Economic and social dimensions } \\
\text { Affordable living options, economic participation, social engagement } \\
\& \text { activities, service programs }\end{array}$ & $\begin{array}{r}\text { Link an affordable physical environment with services and activities } \\
\text { relevant to older people; home as a hub for service delivery and a } \\
\text { base for older people to go out into the wider environment }\end{array}$ \\
\hline
\end{tabular}

Sources: Draws on Diaz Moore 2014, Forsyth et al. 2017, Lawton 1982; and Wahl et al. 2012 
Fig. 1 Population aged 55 and over living alone by age and sex in the United States, 2016. Part A: percent of older people living alone by age group. Part $B$ millions of older people living alone by age group. Source: Joint Center for Housing Studies, Harvard University, tabulations for the American Community Survey 2016

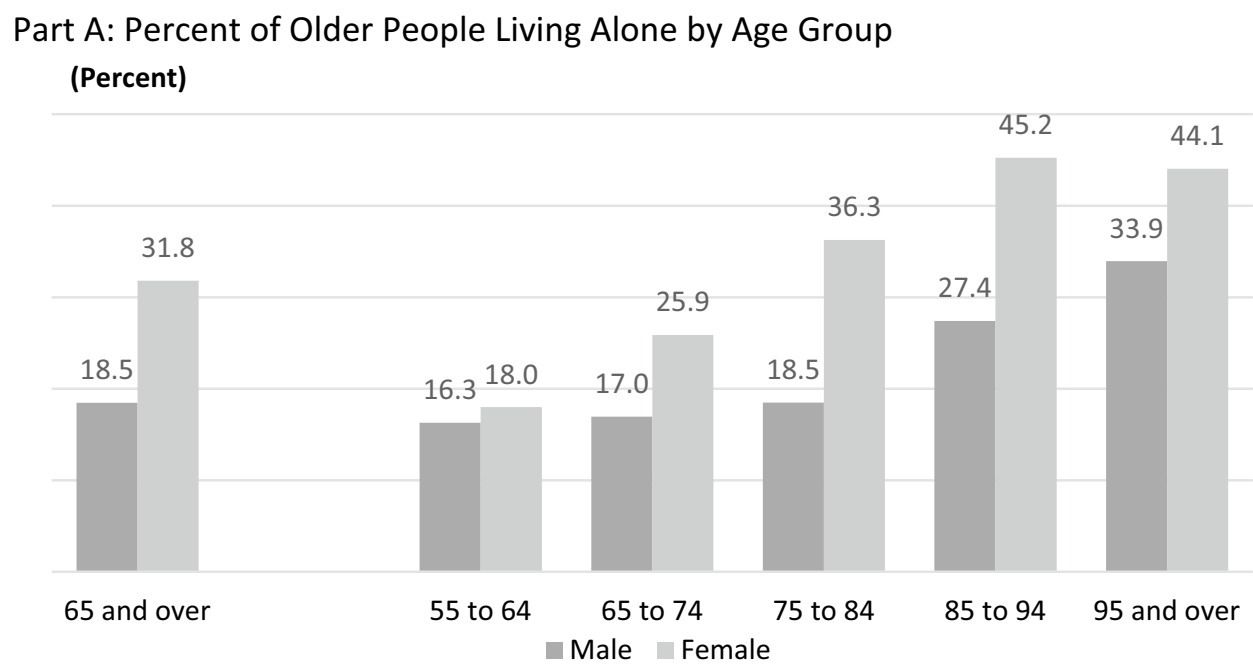

Part B: Millions of Older People Living Alone by Age Group

(Millions)

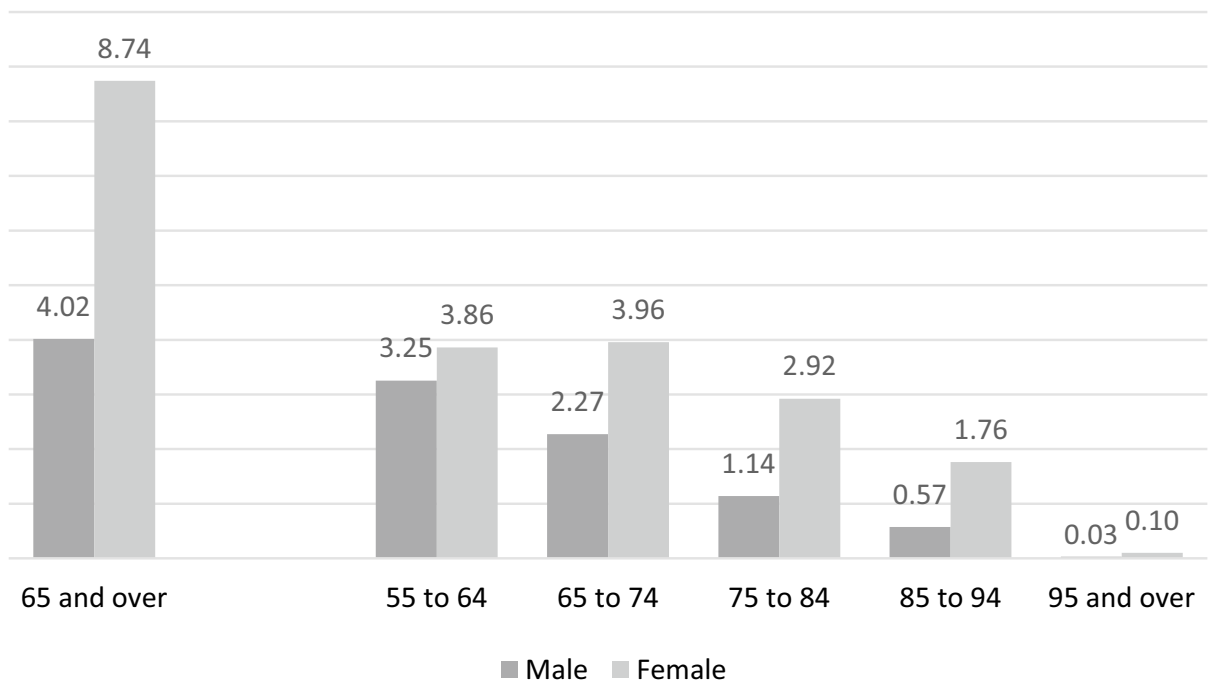

Canada, Finland, Ireland, Spain, the UK, and the United States had childless rates at or over 19\% of those aged 40-44 (OECD 2015). Even having children is not a guarantee of their helping in old age. Daughters who have traditionally provided care are often in the paid workforce, and not all live close to a parent (Kasper et al. 2015). This in an international phenomenon - in 1960, 87\% of Japanese people over 65 lived with their children, but by 2005 it was $47 \%$ (NIA and WHO 2011, p. 23). The full force of this trend has not yet been felt.

Single-person households, particularly those that are female, generally have fewer economic assets. In 2016, in the U.S., according to the American Community Survey, female householders aged 65 and over living alone had a poverty rate of $18.7 \%$ compared with $14.5 \%$ for men living alone and $4.1 \%$ for married couple families. Rates for Black and Hispanic/Latino women aged 65 and over living alone were even higher at 29.2 and $41.2 \%$. In the U.S., compared with married counterparts, such households also have higher rates of disabilities, and more often need to pay for care (JCHS 2016, p. 6).

\section{Trends toward home care}

With lower incomes and greater likelihood of needing paid care, small households will be particularly vulnerable to isolation and unmet physical and social needs. Yet at the same time, policy changes and consumer choices have reduced the percent of older adults residing in nursing homes in many countries. In the U.S., the share of older adults in nursing home residents fell steadily from 1990 to 2015, even as the older population has increased. In 2016, according to the 
American Community Survey, about 1.24 million people over age 65 (2.6\% of the population over 65$)$ were in such facilities, down from about 5\% in 1990. Residents are more likely to be very old; in 2010 , about $10.4 \%$ of Medicare enrollees aged 85-94 and $24.7 \%$ of those 95 and over lived in nursing homes (West et al. 2014, pp. 136-137). However, overall more people are living outside institutions meaning that the balance of support—physical and social—will need to be delivered to their home, neighborhood, and community environments.

\section{Variations and vulnerabilities in the olds}

While older people are diverse, age does bring an increased likelihood of experiencing disability. For the U.S. population over $85,53 \%$ have difficulty walking and climbing stairs; 50\% doing errands alone; $31 \%$ dressing and bathing; $35 \%$ hearing; $29 \%$ remembering, concentrating, and making decisions; and 18\% seeing (West et al. 2014, p. 43). Again, this is an international phenomenon (Lafortune et al. 2007).

Such older people often need help with what are known as activities of daily living (ADLs), typically "eating, dressing, getting into or out of a bed or chair, taking a bath or shower, and using the toilet," and instrumental activities of daily living (IADL) including things like meal preparation, money management, shopping, housework, and telephone use (U.S. National Cancer Institute n.d.). Outside the home, they may have difficulty accessing services because they do not drive and/or live in places lacking services, such as outer suburbs and rural locations.

Having multiple challenges with everyday functioning is often associated with a condition dubbed frailty which affects a very large number of older people. Frailty is not a single, clearly defined condition but rather represents the cumulative interactions of multiple factors. At a minimum, medical definitions focus on having at least three of five characteristics: decline in weight loss (shrinkage), exhaustion, slow gait speed, small amounts of activity, and general weakness measured via grip strength (Fried 2016, p. $3)$. Other features may also be included in broader, more sociological definitions such as cognitive impairment, urinary incontinence, balance problems and falls, difficulty with activities of daily living, diminished ability to give and receive social support, and fluctuations in disability (Clegg et al. 2013; Barrett and Twitchin 2006; Harttgen et al. 2013). Causes are complex and much debated but may be related to advanced physical aging and reactions to a lifetime of stressors (Buckinx et al. 2015).

A study of almost 80,000 people aged 50 and over from Europe and major low- and middle-income countriesChina, Mexico, Ghana, South Africa, India, and the Russian Federation-found high frailty prevalence for those aged 85-89 (21-45\%) and 90 and over (23-47\%) (Harttgen et al. 2013). Other studies of high- and middle-income countries, including the U.S., have found similar numbers (Fried 2016; Clegg et al. 2013). A study of 7439 adults in the U.S. found a substantial group with 1-2 of the five features that commonly define frailty (shrinkage, exhaustion, slow gait, low activity, and weakness). This group includes $45.5 \%$ of those 65 and over, $47.5 \%$ of those $85-89$, and $48.7 \%$ of those $90+$ living in the community (Bandeen-Roche et al. 2015, p. 1429). These are large numbers that deserve to be on the radar screen of urban design.

Socioeconomics also make a difference. Those with low incomes and educational attainment tend to experience frailty earlier, leading to higher rates at any particular age group (Harttgen et al. 2013; Bandeen-Roche et al. 2015, p. 1429). Yet those with high incomes and education live longer and experience frailty, just more likely at older ages. Even if better population health means that people experience fewer symptoms of frailty at younger ages, growing longevity means there will be large numbers of people in their $80 \mathrm{~s}$ and beyond facing this challenge. In addition, the Bandeen-Roche et al. (2015) study found variation across race/ethnicity. While non-Hispanic whites aged 65 or over had a frailty rate of $13.8 \%$, African-Americans and Hispanics of the same age range had frailty rates of 22.9 and $24.6 \%$, respectively. The pre-frail numbers for all groups were similar, however, ranging from 45.3 to $46.5 \%$ of those 65 and over.

While disability rates among those who are very old have been declining a little in countries like the U.S., countering that is the larger numbers of the very old (He et al. 2016; Chernew et al. 2016). More importantly, the problems of old age are not static, but emerging over time, incrementally or more suddenly, through a crisis. A person's environment may need to accommodate new needs and limitations. Whatever the situation, most people reaching advanced age will experience some limitations, and that is particularly the case for those with other disadvantages. If people want to age in place, home and community environments need to be able to support such circumstances, or there need to be nearby alternatives for aging in community.

\section{Environmental fit, needs, and urban design}

Much of the work on environments for older people dealing with impairments has focused on the house. For example, work by the Joint Center for Housing Studies using data from the 2011 American Housing Survey found that "less than $4 \%$ of single family homes, the most common form of housing for older adults, offers three of the most critical accessibility features... (single-floor living [with bedroom and bathroom on the main floor], extra-wide hallways and doors, and zero-step entrances)" (JCHS 2016, p. 9). Issues with home design, adaptation, maintenance, and 
location have been identified internationally (Barrett and Twitchin 2006, p. 148; Byles et al. 2014).

The scale of urban design is typically seen as being larger than the home-the block, district, or beyond. A number of the solutions we outline in this paper do deal with housing but at this larger scale, providing innovative ways of clustering housing to help provide services or social supports, or dealing with aging in place at a neighborhood or district level.

The home is also connected to a wider network of services, accessed by older people venturing out or through service people coming to the home, particularly for those services related to housework or personal care such as bathing, dressing, or eating. Both types of service delivery can be challenging due to home location. Of those over 65 in the U.S., roughly half live in rural areas or in metropolitan areas with less than 1 housing unit per acre, $28 \%$ in areas from about 17-3.2 units per acre (broadly suburban), and only $23 \%$ in areas more than 3.2 units per gross acre at the census tract level (JCHS 2016, p. 30). Low density and lack of transportation options can make it more difficult to engage with one's community-yet even in more dense urban environments problems can occur. For example, vibrant districts may be congested, with noise, traffic, uneven lighting, and potential for being bumped, discouraging older adults from venturing into public (Hunter et al. 2011; Clark and Nieuwenhuijsen 2009).

Challenging locations provide a rationale for some of the purpose-built housing models that provide services and housing together in one location. Research findings also show that older people living with higher proportions of those of similar age have fewer symptoms of depression and better self-rated health (Clark and Nieuwenhuijsen 2009), as well as higher rates of formal volunteering (Park et al. 2017). Yet such models are not for everyone, making the case for other alternatives.

Overall there are few perfect answers. Core cities have many services but also risks such as traffic and potential for falls. Suburban town centers and small towns might offer services and supports as well as easier mobility, but many suburban residents are not in such centers and risk isolation, as do those in very low density and rural areas (Forsyth 2014). Of course, the situation is quite different in a place like China where densities are very high, but anecdotal evidence points to isolation among older people in new high-density environments where they may have moved to live with working children but spend much of the day without them and far from their old friends. Very supportive physical environments might allow frail older people to function better for longer, but these require a coordinated set of solutions going beyond physical design, as we describe below.

\section{Solutions}

Solutions to support people living alone in the community and with multiple conditions frequently involve family and professional paid support, service programs, and healthcare interventions outside the domain of urban planning and design. However, there are opportunities to intervene. These interventions may involve a traditional menu of purpose-built facilities such as nursing homes (though fewer live in them, they are still important for post-acute care and often at the end of life), continuing care retirement communities, and active retirement communities. Increasingly, options are available that combine independent living with a limited set of supportive services that seek to prolong the time older adults are able to live in the community, making community design more important (Jones et al. 2008, pp. 61-62; Appendix).

Alongside these trends have been innovations at the scale of the neighborhood and dwelling cluster where urban designers and planners have some role, though often by collaborating with other fields (Table 2). These include enriched neighborhoods, collective care, and all-age neighborhoods; purpose-built serviced housing clusters; and small-scale intergenerational models, all described below. These are supplemented by new mobility and delivery options. These models are international, and we draw on documented and photographic examples from the Netherlands, U.K., and U.S., as well as Australia, China, Denmark, Korea, Singapore, and Sweden.

The following sections describe each model in turn, provide examples, and reflect on implications. Urban planners and designers will be more involved in some of these strategies than others (Frye 2014; Table 3). However, these models require, or would benefit from, collaboration between different professions and sectors such as business, government, education, and community. Planners and urban designers excel at such linkages and could be a key part of making places more liveable for the growing population of frail older adults.

\section{Neighborhood level}

\section{Enriched neighborhood}

This approach brings together organizations from different sectors-such as government, health, business, and nonprofits-using multiple strategies to upgrade an existing place. It typically requires a good deal of expert input but involves at least some participation on the part of older people. 


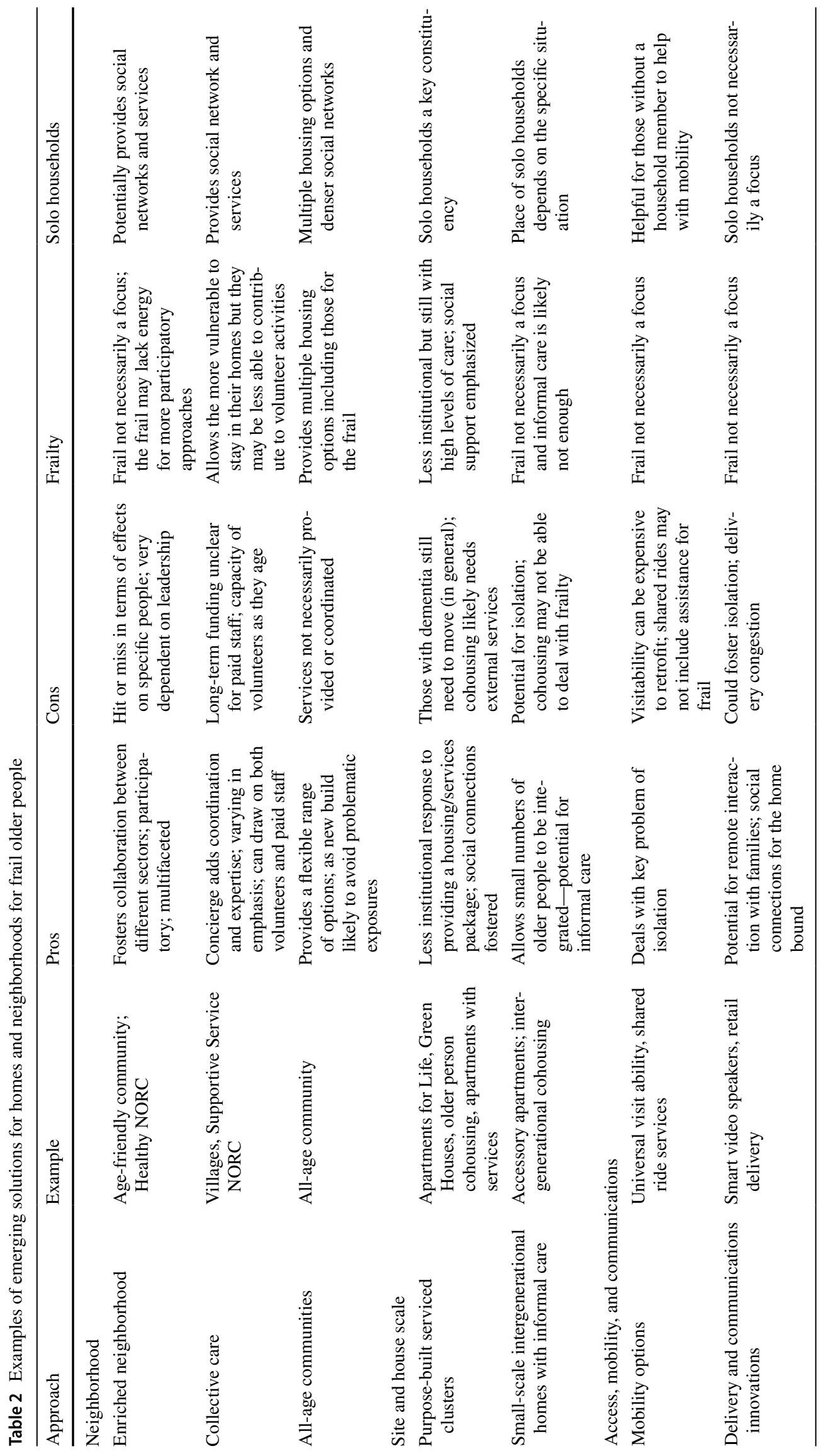


Table 3 Roles of urban designers and planners in emerging solutions

Approach Urban design role

Neighborhood

Enriched neighborhoods, collective care, and all-age communities Help ensure interventions to upgrade public realm for safety, physical activity, sociability, and mobility, and are more spatially comprehensive and ambitious; includes linkages beyond the neighborhood and over time Promote and develop wider range of housing options

Locate service hubs such as adult day care centers and new forms of spaces for well-being (e.g., expanded library or parks facilities)

Contribute expertise in public participation over urban improvements

Site and house scale

Purpose-built serviced clusters and small-scale intergenerational homes with informal care

Access, mobility, and communications

Mobility options; delivery and communications innovations
Integrate clusters into the wider community with public realm improvements and shared facilities such as restaurants and community meeting places

Design larger developments to fit into the surroundings and be attractive to a range of age and ability groups among the older population

Ensure that scattered developments have adequate accessibility features in the neighborhood public realm

Provide low-tech upgrades to the public realm related to universal design principles, allowing for assistive technologies both current and proposed, e.g., potential autonomous wheelchairs or helper robots in the public realm Engage innovations in service delivery and communications which may affect urban service locations and formats

Pay attention to urban design aspects of regional scale transportation systems and how transportation can be made to serve older adults, e.g., age-friendly transit-oriented development

Highlight urban-scale design needs of older people as new technologies are developed

\section{Age-friendly communities}

Launched in 2007 by the World Health Organization (WHO), age-friendly communities build on earlier WHO work on healthy cities as well as various city-level initiatives. Initial WHO work was global, working with 35 cities from around the world. The organization conducted 158 focus with people 60 or over $(N=1485)$; as well as with caregivers $(N=250)$; and service providers $(N=515)$ (Plouffe and Kalache 2010). The focus group themes were similar in both the developed and developing world: "The city's landscape, buildings, transportation system, and housing contribute to confident mobility, healthy behaviours, social participation, and self-determination, or, conversely, to fearful isolation, inactivity, and social exclusion." (Plouffe and Kalache 2010, pp. 237-238; WHO 2007). Also important was designing a city for multiple age groups and capacities, not just the old. By 2017, WHO's Global Network for Agefriendly Cities and Communities (GNAFCC) had over 500 members and there are other communities and organizations involved in such work (WHO 2007).

New York was an early adopter in 2007 and exemplifies the range of activities an age-friendly city can provide. By 2017, the New York organization released an updated plan with 86 initiatives across six areas: health and social services, housing, public spaces and transportation, public safety, communication and information, and community and civic participation (Age-Friendly NYC 2017). While these initiatives could have come about without Age-Friendly NYC, the effort has likely drawn attention to the needs of older people in these six arenas and enhanced coordination among public agencies, institutions and private entities, and the public.

\section{Healthy NORCs}

A naturally occurring retirement community or NORC is merely a high concentration of older people residing in a specific area or building, occurring because they have moved in (e.g., coastal areas, well-located apartment building), have aged in place, or young people have moved away. At their base, NORCs may not be particularly healthy locations in terms of environments or services but a number of proposals aim to change that. Two interesting ones are the Healthy NORC, dealt with here, and the Social Support NORC discussed later. The Healthy NORC is focused not on providing health care but on creating places that "increase activity, decrease stress, and provide a sense of community and well-being" (Masotti et al. 2006, p. 1167). This is operationalized as a place where it is easy to get out and about by walking, with transit, social activity, older person participation in governance, and senior-oriented private businesses 
(Masotti et al. 2006). Masotti et al.'s concept is on the face of it oriented toward the more robust or active type of older person but one can imagine layering on features for those who have various disabilities. At present, it is more a concept than a movement but it could obviously be applied in many locations.

\section{Implications}

These are powerful models that may involve improvements to public facilities, open spaces, transportation, and general community life. They help build social networks in places, making them similar to age-specific retirement communities (Alidoust et al. 2017). While led by experts, they do include the participation of older people. They are not particularly aimed at the frail and small households, and indeed those who are quite frail may not be able to participate and articulate their needs. Something similar could be said of those with dementia, as they too have specific needs (Mitchell et al. 2004). Urban designers and planners could help make these programs more comprehensive in terms of spaces covered and more ambitious in changing the public realm.

\section{Collective care}

This model helps people living within their own homes access services in a specific area, achieving some aspects of age-specific housing while remaining in their existing dwelling. A concierge or coordinator connects residents to a mix of volunteer, public, and private services. Residents live near each other and can help with social support (Greenfield et al. 2013).

\section{Village movement}

Started in Beacon Hill in Boston in 2001, the Village helps those over 55 get some of the benefits of moving into a retirement village without needing to move. Social activities, companionship, home care, wellness, and home maintenance help is accessed through a non-profit membership model that mixes members' own volunteering, a paid organizer, and referrals to vendors who are pre-vetted (McDonough and Davitt 2011, p. 530; Greenfield et al. 2013). Older people play a strong leadership role though it does vary somewhat among Villages (Capital Impact Partners 2015). Membership fees are relatively modest (in the hundreds of dollars in the U.S., often with discounts for those with low incomes) and mainly pay for the coordinator. Residents build social connections through potluck dinners, book clubs, and other social activities (McDonough and Davitt 2011, p. 530).

An evaluation identified several organizational arrangements including the grassroots model (a stand-alone nonprofit), a sponsored Village (supported by existing social services agencies), a hub and spoke network of smaller Villages, and a model where people earn time dollars for volunteering which can help lower fees (Capital Impact Partners 2015). The model may well need to be modified as members get older and have more disabilities and volunteering becomes more difficult for a higher percentage (Greenfield et al. 2013).

\section{Supportive service NORCS}

As noted above, NORCs are areas where a concentration of older people live. NORCs can, however, be upgraded by adding coordinated services, a concierge-type staff member (such as a social worker), activities such as walking clubs or educational programs, transportation services, and more age-friendly environments (Ivery et al. 2010; Greenfield et al. 2013; Greenfield 2016). These Supportive Services NORC organizations also try to enhance interaction among residents. The mix of services and programs is similar to the Village model, but it is more social services-oriented and provider-led. The model was first systematically developed in New York City in the 1980s in a co-op apartment block where people had aged in place; the co-op board created a program that contracted with outside agencies for services (Lawler 2001). In the 1990s the City of New York identified additional affordable housing buildings taking this form (New York State office for the Aging n.d.). However, the model has also been replicated in lower density areas (Ivery et al. 2010).

Greenfield et al. (2013) interviewed program leaders in 69 Villages and 62 Supportive Service NORCs and found those in NORCs had lower incomes, were older, and had more functional impairments than those in Villages. The more staff-driven model of the Supportive Service NORCs was a better fit for the capacities of this group. While the Supportive Service NORCs did try to encourage interaction with neighbors so they could support one another, Greenfield's (2016) interviews with participants confirmed help from neighbors was limited and typically based on preexisting relationships. Participants preferred professional help with finances, medical issues, very time-consuming tasks, or tasks that might violate norms of privacy. As people became older they were less able to provide help and more likely to need it. This is similar for most models, of course, but highlights the need for external help in all these cases, particularly for those who are older.

The Supportive Services NORC is rather similar to the Israeli "supportive communities" approach that started in the 1990s. In that model each community has about 200 members living in their own homes, with two to three staff members who coordinate services, social support, and volunteers (Billig 2004). It also includes a 24-h emergency call service, medical services, transportation related to medical 
appointments, and home repairs. Similarly, the Vermont SASH (Support and Services at Home) program coordinates medical and other services for older people clustered in affordable housing developments and some others, in an effort to reduce healthcare costs and prolong independence in the home (RTI International and LeadingAge 2016). Adult day care centers can also be integrated into such supportive communities (Fig. 2).

\section{Implications}

These models allow people to stay in their own homes but enjoy a more coordinated set of services and social activities. The Village model is attractive as it draws on the energy of older people themselves, but it is unclear how well it could deal with the very frail who may be unable to volunteer, as well as those with generally fewer resources. The Supportive Services NORC has some advantages of professionalism but requires a funding stream. One can imagine further developing a hybrid approach, something that is already emerging, with volunteering where possible supplemented with outside services. The models have potential to provide social interaction as existing social networks fray. An unintended consequence may be reduced housing turnover as older adults remain in their homes longer than in the past. For planners and urban designers, both would mean older people being more likely to stay in existing neighborhoods and not move to purpose-built housing, making the age-friendly physical upgrading of neighborhood environments and homes more important.

\section{All-age neighborhoods and towns}

All-age communities are new-build alternatives to the largescale active retirement community. They integrate services for older adults into a wider redevelopment plan or potentially a greenfield new town with several hundreds or even thousands of units. Older people will only be part of the population but will have multiple housing options (Jones et al. 2008, p. 53). This is a less well-developed concept with few existing examples.

\section{Holly Street}

An example that has not had published evaluations but is still worth examining is the Holly Street Comprehensive Estate Initiative in London. This involved rebuilding a large public housing estate that included a substantial population that had moved in during the 1960s and aged in place. Development started in the 1990s and is continuing; when it is completed it will have nearly 1000 homes in total (Hackney 2016). In addition to housing for the general population, the redevelopment has included a range of new housing options for its older population including smaller units, a tower block with concierge and accessibility features, a serviced housing/assisted living scheme that also included a senior center with adult day care, and 40 apartments for frail older people (Hanson 2001, p. 47). Such a model is easily transferable to new-build neighborhoods. Hanson (2001, p. 47) notes that this is much more than just a mix of housing types and tenures as it includes social services, health, and transportation elements, all of which require collaboration among various agencies.

\section{Implications}

While requiring some more coordination than a bare-bones new or redeveloped neighborhood, the all-age neighborhood model has the potential to substantially increase quality of life for residents. It is transferrable to a wide variety of environments, including areas where housing and service options are retrofitted into existing areas. Limitations include finding land and coordinating different developers, service providers, and government agencies; these are substantial challenges and few such environments have been developed. Planners and designers could advocate for all-age approaches and ensure that over the long process of building that the development or redevelopment continues to include a range of housing, services, and open space options for older people. Design—of housing clusters and the public realm-is key.

\section{Site and dwelling scale}

\section{Purpose-built serviced clusters}

As noted earlier, a range of age-specific housing options is already available (Appendix). For those with multiple conditions, innovations with high-service levels are most crucial. Facilities such as nursing homes have been the subject of experimentation in many places including Australia, Sweden, and the United States starting in the 1980s and 1990s (Forsyth 1992; Jones et al. 2008, p. 57; Sharkey et al. 2011). Typically, the aim has been to break down the scale of the facility into much smaller home-like clusters allowing a more domestic-scale and home-like atmosphere. Clusters can stand alone as large group homes, or they may be clustered or stacked vertically into campuses or multi-storey configurations. In addition, some have taken a mixed-use apartment format.

The Green House is an innovation in nursing home design, disseminated quite widely with help from the Robert Wood Johnson Foundation but reminiscent of earlier models like the U.K.'s Abbeyfield housing (Abbeyfield 2018). This model occurs both as free-standing operations and as part 


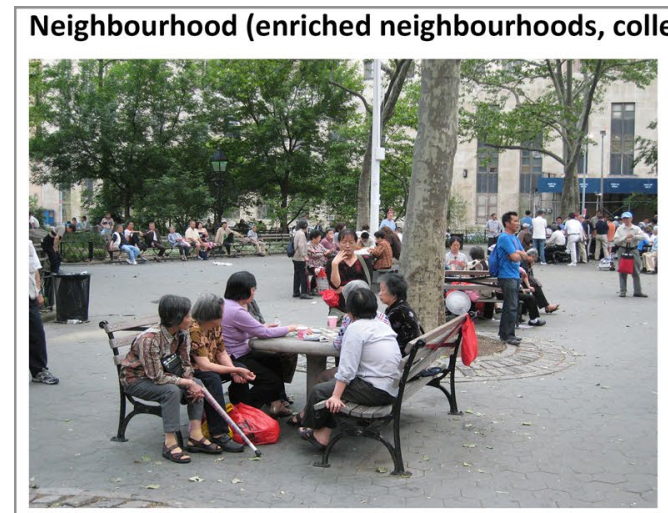

New York, an early age-friendly community, provides options for older people to socialize. Urban designers could enhance these features (New York, U.S.).

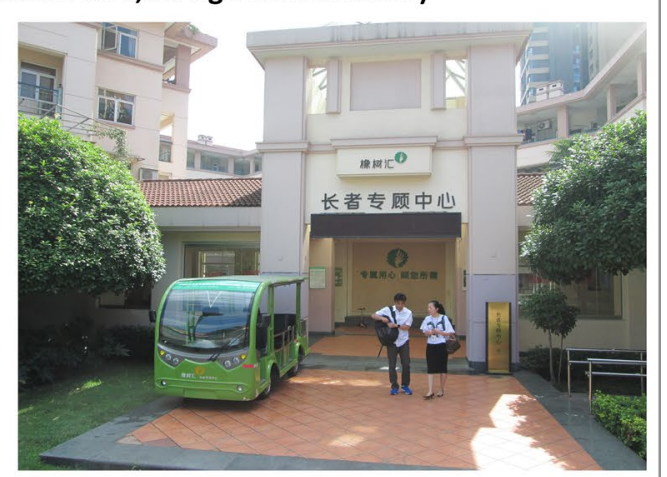

Entrance to an adult day care center integrated into a rental housing development, similar to that found in a NORC (Chengdu, China).

\section{Site and house scale (serviced clusters, intergenerational homes)}

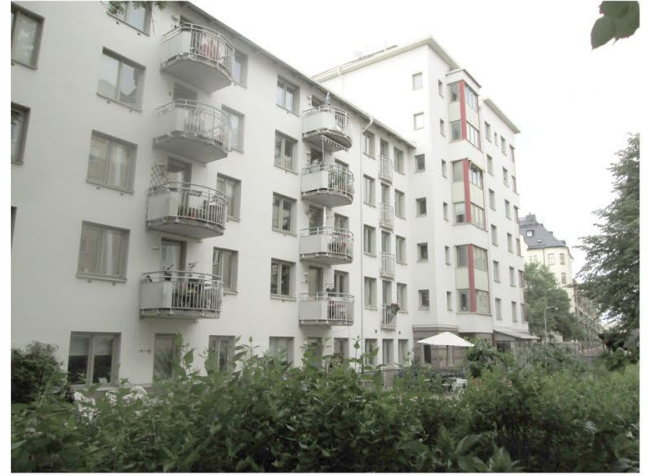

Elder cohousing and other collective housing types can take the form of a single apartment building. Urban design could add public realm improvements and shared services (Stockholm, Sweden).

\section{Access, mobility, and communications options}

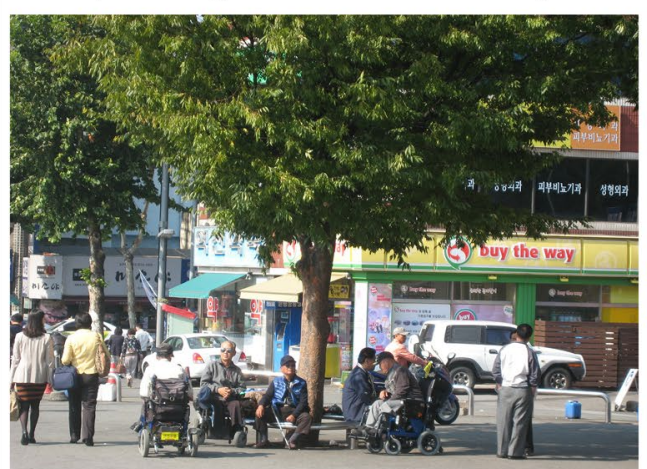

A public plaza with seating options for people using different kinds of mobility aids provides options for those with different disabilities to socialize (Daejeon, Korea).

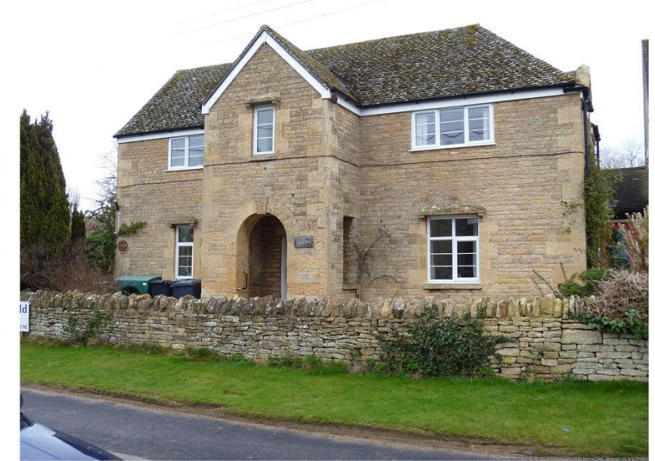

More domestic -scaled alternatives, such as this Abbeyfield House, can receive urban design attention to mobility infrastructure (Chadlington, U.K.).

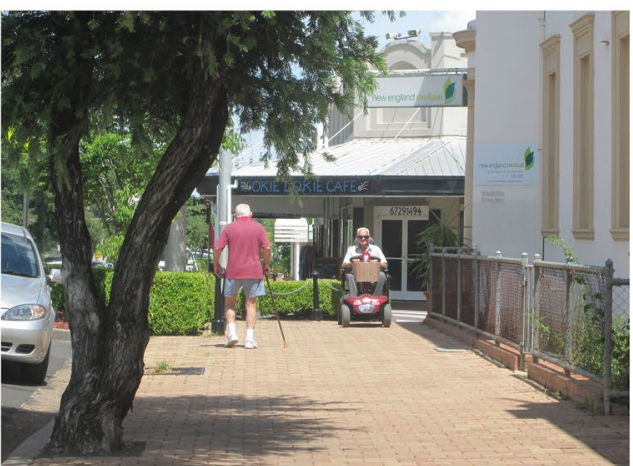

Wide footpaths and curb cuts allow mobility. Public realm design will likely accommodate new forms of mobility technologies (rural town, Australia).

Images by the authors, Michael Dibb (https://www.geograph.org.uk/more.php?id=2949502)

Fig. 2 Examples of environments for older people with neighborhood, site, and mobility improvements 
of continuing care retirement communities. An individual house typically has 9-12 residents (Sharkey et al. 2011). Services are provided more flexibly than in traditional nursing homes with staff, renamed Shahbazim, performing multiple functions in a flatter organizational design focused on maintaining resident function. Physically they include studio apartments around a shared dining, open kitchen, and living area with access to outdoors (Jenkens et al. 2011).

A review of evidence found capital costs are slightly higher than traditional models, though the traditional models had less space and fewer amenities. However, detached Green Homes might well be comparable or less expensive due to opportunities to meet health and safety regulations less expensively in smaller structures. Operating costs were similar to other nursing homes (Jenkens et al. 2011). Satisfaction and health outcomes were improved in part because there was a shift away from time spent in administration toward direct care (Sharkey et al. 2011; Jenkens et al. 2011). The Sharkey et al. (2011) study is particularly interesting as it matched 14 Green Homes to traditional nursing homes, some run by the same organizations and used site visits, government data from Medicare and Medicaid, staff surveys, and 3-day activity logs to closely track operational practices showing the benefits of the Green House model.

\section{Apartments for life}

Another innovation is to build housing where services can be increased to very high levels in the same unit. One model is created by Humanitas Housing in the Netherlands. Typically, this is an apartment cluster of 100-250 units with an attached restaurant that also serves the public, and associated services (Jones et al. 2008, p. 57). It is possible to move in and stay in the unit as care needs rise, including the need for skilled nursing care. Those with advanced dementia, however, are housed in a small cluster like a Green House.

Units are large from 70 square meters up to 300 with balcony space and accessibility features for wheelchairs and stretchers, lever handles, adjustable sinks, computerized keys, and the like (Birkbeck 2014). In addition to nursing staff, volunteers are active and receive a small stipend. For services, residents can use Humanitas providers but also others. "Typically, each development will offer access to personal care, nursing care, a psychologist, social worker, dietician, speech therapist, GP and other health and care services. These are always based among the ground-floor facilities as though part of the usual high-street provisions" (Birkbeck 2014, p. 101)

\section{Apartments with services}

Elsewhere there are similar models that are not quite as coordinated or where services are not as extensive as one might receive in a nursing home. A recent development in Singapore, "Kampung Admiralty" or "Village Admiralty," is located next to a transit stop. It vertically combines senior housing with other public and intergenerational access spaces, including an active aging hub, retail and commercial spaces, and neighborhood amenities, e.g., a hawker center/food court, community gardens/outdoor spaces, and a childcare center (Straits Times 2017). Combined with Singapore's social services system, this creates something akin to Apartments for Life. Increasingly, providers of independent housing for older adults are adding additional services; the issue for the frail is whether these are sufficient to meet their needs.

\section{Elder cohousing}

Cohousing involves groups of 10-50 dwellings sharing common areas including a dining and kitchen area, typically using a condominium style of ownership. Some space in the unit is traded off for the common space (Wardrip 2010). While initially cohousing developments were intergenerational (see next section), they were, in fact, generally occupied by younger or middle-aged people. As a response, cohousing for those of middle-age and above has been developed as an option with examples in the Netherlands, Denmark, Sweden, and United States (Jones et al. 2008, p. 5; deLaGrange 2014).

Proponents are hopeful this can be a collective model for self-help (Wardrip 2010; Durrett 2009). However, the form of help is social support rather than help with health issues or activities of daily living. For those, people will need to tap into wider support networks (as in a Supportive Service NORC or Village, or individually obtained care). That is, as people become increasingly frail, cohousing will be more like other housing types in requiring support from outside. The classic Danish example is Munksogard, a 20-unit senior cohousing development that is part of a campus with 100 total units. Opened in 2000, there is a clear split between informal social support provided by cohousing residents and the kind of home healthcare, such as help with bathing and dressing, provided by the government (Durrett 2009, p. 57).

\section{Implications}

Obviously there has been quite a lot of recent innovation at the site and dwelling scale. Models show how high levels of informal social support and even fairly intensive healthcare can be provided in purpose-built facilities at the scale of the group home or apartment building and thus integrated into the general community. The issue for all these models is to find land in well-serviced and well-designed areas and to provide high levels of services for the very frail while still being attractive to more robust older people. Like many of 
the solutions in this paper, this requires some initial up-front costs for accessibility features, which are however minor compared with retrofitting later (Gobtop and Memken 2005; Judd et al. 2010). These operate at the smallest scales of urban design: the site and block. However, they have implications for the surrounding areas in terms of supporting physical and visual access across a range of abilities.

\section{Small-scale intergenerational housing}

Modeled on intergenerational family compounds and very small villages, small numbers of older people are housed in existing or new-build facilities along with people of other ages. These may either be for single-person households or couples, as in the smallest scale of accessory apartments, or in small clusters as may occur in a cohousing scheme. The idea is, in part, to promote social support and informal care giving.

\section{Cohousing}

The cohousing format has potential as a base for intergenerational housing (Jones et al. 2008, p. 58). However, typically those starting cohousing developments have been younger and it has not always been obvious how older people would fit over time, particularly as they needed more substantial care. A review of the issue found on the Cohousing Association of the United States web site indicated numerous challenges: a lack of accessibility features, issues with "decision-making, hearing well in meetings," participation in chores and cooking, and needs for substantial assistance (deLaGrange 2014). DeLaGrange reported anecdotes about turnover meaning younger people did not remember the large amount of work put in earlier by seniors to establish a community, and even in places with stable residents, older people could feel isolated. In cohousing developments that were more supportive, there was often little discussion about longer term implications of increased service needs among residents, including services needed from outside. Overall this is a complex model to use at a large scale, particularly for frail older people.

\section{Accessory dwelling units}

An accessory dwelling unit is an additional unit either within a home, attached to it as an addition, or as a small building in the yard. One of the earliest large programs for this was the 1975 Victorian moveable units or "granny flat" initiative in Australia, available both as market-rate and subsidized units. This program used portable free-standing dwellings suitable for location in the yards of larger homes to promote intergeneration households while allowing privacy (Forsyth 1992, p. 57). Whether mobile or not, the idea is similar: the older person may live in the unit, or they may live in the main house with a caregiver, family member, or tenant in the apartment.

This model has excited interest in those wanting to densify lower density areas and diversify the housing to incorporate smaller units, helping accommodate smaller households (Duff 2012). It can also provide a way to encourage informal care-for example an accessory apartment tenant may do gardening or snow removal, or a family member in the main dwelling may make meals and take the older person shopping. Though accessory dwellings can be made to be wheelchair accessible, many are not (e.g., the carriage-house style apartment over a garage). The cost of construction or remodeling can be high.

\section{Implications}

These are two models that can provide modest support and, if combined with some of the service models, have potential to serve an important population. They may be particularly attractive to those living alone or families receptive to intergenerational living. They do not guarantee high levels of service, however. Planners and designers would need to ensure that they are well designed and located. Particularly interesting would be the idea of creating supportive neighborhood contexts for areas with multiple accessory dwellings.

\section{Mobility, delivery, and communications}

Technologies that enhance mobility for older people or help bring goods, services, and social connections to their homes change the relationship of the person to the neighborhood and wider world (Frye 2014). Robust older people may be interested in health-promoting activities such as walking, cycling, and using social media to supplement social networks. For those who have more health problems, however, technologies can be particularly important in preventing isolation and accessing health and other services. Much technology is aimed at the individual level (e.g., new kinds of wheelchairs and walkers, home library, or grocery delivery); these are useful, but here we focus on strategies at the scale of the neighborhood, where they may be implications for neighborhood design.

Generally, interventions for frail people include both low-tech and high-tech strategies. For example, a low-tech approach to mobility may involve locating housing in town centers, so walking distances are short; upgrading pedestrian paths so people can use canes, walkers, and wheelchairs more easily; and making homes and businesses visitable to those with various disabilities (such as is required of new developer-built housing constructed in the state of Vermont in the U.S.). Such strategies can be built into regulations at municipal, state, or national levels. A higher-tech option 
would involve variations of shared ride services (Uber, Lyft, and demand-response transit) that include assistance at trip ends getting people to their final destinations (Mackett et al. 2008). This is a fast-moving area that has already changed urban area (e.g., online shopping changing the retail landscape). More change is likely. For example, assistive technologies might help older people get out and about more easily but could also pose challenges-imagine pedestrian path congestion from helper robots.

\section{Implications}

In this time of rapid change, low-tech solutions such as better pedestrian paths and well-located housing, as well as opportunities for face-to-face communication, are still important. Equity issues will also be key. Urban designers and planners can be advocates for ensuring physical features, transportation services, and housing options are distributed to lower-income neighborhoods and those with older adults, while, at the same time, monitoring how changing technology requires new design and planning interventions.

\section{Conclusion}

The number of older people will increase during the next century and many will have multiple health problems, need help with daily tasks, and will live alone. This paper started with two questions. What are the challenges that cities and regions will have to face due to this increase in vulnerable, often single-person households? What are some planning and design strategies to better adapt places to this new reality-both already tested and plausible?

Having safe, accessible homes and neighborhoods can be very helpful in allowing older people to manage their frailty and maintain independence. This is particularly important for the growing numbers of old people living alone. Housing options that allow people to either age in their own homes with added services or move to more home-like purposebuilt environments are growing and could be fostered by planners and urban designers. Some of these options will be more widespread than others but variety is key; one size will not fit the range of older adults or locations. Aging also means that needs and preferences change over time-sometimes gradually, but sometimes quite rapidly as with health crises. While many people say they want to age in place, this might not mean in their exact house or apartment (Roy et al. 2018). Other living environments, including those within the same community, may be more suitable and have the additional benefit of useful housing turnover.

In terms of urban planning and design, much of the action is at the intersection of physical place, economic and social dimensions (including services), and the person-how to make sure that people are supported when and where they need it. As the older population grows, it will be important that awareness of the needs of those with multiple health problems be incorporated into the work of a host of public agencies particularly at the local level. These include public works, transportation, parks and recreation, as well as planning and housing. Urban designers can have a key role to play in fostering this collaboration (Table 3). Urban designers and planners working at all scales can promote a more comprehensive view and emphasize the importance of the public realm and clustering of services and activity spaces, serving as important champions of this population.

However, with few exceptions, planners and urban designers to date have paid insufficient attention to those older people dealing with multiple physical and other challenges, whether because this population is not visible in society or the solutions require significant coordination and innovation. Yet helping older people remain safe, engaged, and able to access the services they need has both social and economic benefits to society and is arguably an ethical obligation for these fields.

This paper highlights frailty and living alone; future research could examine the specific housing and environmental needs and solutions for those with dementia, other disabilities such as hearing and vision problems, or cultural isolation. As the older populations grow, recognizing the heterogeneity of those in their later years is key to providing better environments.

Open Access This article is distributed under the terms of the Creative Commons Attribution 4.0 International License (http://creativeco mmons.org/licenses/by/4.0/), which permits unrestricted use, distribution, and reproduction in any medium, provided you give appropriate credit to the original author(s) and the source, provide a link to the Creative Commons license, and indicate if changes were made.

\section{Appendix: Current types of older person-specific housing and neighborhood interventions in higher income countries}

\begin{tabular}{lll}
\hline Traditional models & Typical example & Recent version* \\
\hline Residential aged care & $\begin{array}{l}\text { Nursing home, } \\
\text { skilled nursing } \\
\text { facility }\end{array}$ & Green house \\
& CCRC & Apartment for life \\
$\begin{array}{l}\text { Continuing care } \\
\text { retirement com- } \\
\text { munity }\end{array}$ & \\
Extra care housing & $\begin{array}{c}\text { Assisted living in } \\
\text { U.S., sheltered } \\
\end{array}$ & \\
& housing in U.K. & \\
\hline
\end{tabular}




\begin{tabular}{|c|c|c|}
\hline Traditional models & Typical example & Recent version* \\
\hline $\begin{array}{l}\text { Service enriched } \\
\text { housing }\end{array}$ & $\begin{array}{l}\text { Independent living, } \\
\text { sheltered housing }\end{array}$ & \\
\hline $\begin{array}{l}\text { Retirement com- } \\
\text { munity }\end{array}$ & $\begin{array}{l}\text { Active adult retire- } \\
\text { ment community }\end{array}$ & $\begin{array}{l}\text { Older person cohous- } \\
\text { ing }\end{array}$ \\
\hline $\begin{array}{l}\text { Group or shared } \\
\text { housing }\end{array}$ & Group home & \\
\hline Home care & Home care & Villages, NORC \\
\hline a la carte services & $\begin{array}{l}\text { Meals on wheels, } \\
\text { paratransit }\end{array}$ & $\begin{array}{l}\text { New delivery and } \\
\text { mobility—online, } \\
\text { shared economy, etc. }\end{array}$ \\
\hline
\end{tabular}

Drawing on: Jones et al. 2008, pp. 61-62; paper above

* Note: This column includes some of the innovations noted in the main paper but others are dealing with quite difference scales

\section{References}

Abbeyfield. 2018. Abbeyfield web site/. https://www.abbeyfield.com/. Accessed 1 Oct 2018.

Age-Friendly NYC. 2017. New Commitments for a City for All Ages. http://www.nyc.gov/html/dfta/downloads/pdf/age_friendly/AgeFr iendlyNYC2017.pdf. Accessed 1 Oct 2018.

Alidoust, S., C. Bosman, G. Holden, H. Shearer, and L. Shutter. 2017. The spatial dimensions of neighbourhood: how older people define it. Journal of Urban Design 22 (5): 547-567.

Baltes, P.B., and M.M. Baltes. 1990. Psychological perspectives on successful aging: The model of selective optimization with compensation. In Successful Aging: Perspectives from the Behavioral Sciences, ed. P.B. Baltes and M.M. Baltes, 1-34. Cambridge, UK: Cambridge University Press.

Bandeen-Roche, K., C.L. Seplaki, J. Huang, B. Buta, R.R. Kalyani, R. Varadhan, Q.-L. Xue, J.D. Walson, and J.D. Kasper. 2015. Frailty in older adults: a nationally representative profile in the United States. Journal of Gerontology: Medical Sciences 70 (11): 1427-1434.

Barrett, P., and S. Twitchin. 2006. The living environments of community-dwelling older people who become frail: another look at the living standards of Older New Zealanders Survey. Social Policy Journal of New Zealand 28: 133-157.

Bell, F. and M. Miller. N.d. Life tables for the United States Social Security Areas 1900-2100. https://www.ssa.gov/oact/NOTES/ as116/as116_V.html. Accessed 1 Oct 2018.

Billig, M. 2004. Supportive communities: an optimal arrangement for the older population? Journal of Sociology and Social Welfare 31 (3): 131-151.

Birkbeck, D. 2014. Happy Meals: Finding happiness with Hans Becker and the Humanitas care model. Architectural Design 84 (2): 94-101.

Buckinx, F., Y. Rolland, J.-Y. Reginster, C. Ricour, J. Petermans, and O. Bruyère. 2015. Burden of frailty in the elderly population: perspectives for a public health challenge. Archives of Public Health 73: 19.

Byles, J.E., L. Mackenzie, S. Redman, L. Parkinson, L. Leigh, and C. Curryer. 2014. Supporting housing and neighbourhoods for healthy ageing: findings form the Housing and Independent Living Study (HAIL). Australasian Journal on Ageing 33 (1): 29-35.

Capital Impact Partners. 2015. Sustaining the Village Movement: Lessons from Pioneers about Village Business Models and Sustainability. https://www.capitalimpact.org/wp-content/uploads/2015/10/2015Sustaining-The-Village-Movement.pdf. Accessed 1 Oct 2018.

Carmona, M., T. Heath, T. Oc, and S. Tiesdell. 2003. Public Places, Urban Spaces: The Dimensions of Urban Design. Oxford: Architectural Press.
Chernew, M., D.M. Cutler, K. Ghosh, and M.B. Landrum. 2016. Understanding the Improvements in Disability Free Life Expectancy in the U.S. Elderly Population. NBER Working Papers. https://scholar.harvard.edu/files/cutler/files/w22306.pdf. Accessed 1 Oct 2018.

Clark, P., and E.R. Nieuwenhuijsen. 2009. Environments for healthy ageing: A critical review. Maturitas 64: 14-19.

Clegg, A., J. Young, S. Iliffe, M.O. Rikkert, and K. Rockwood. 2013. Frailty in elderly people. Lancet 381: 752-762.

deLaGrange, K. 2014. Elder cohousing-How viable is cohousing for an aging population? http://www.cohousing.org/elder-cohou sing. Accessed 1 Oct 2018.

Diaz Moore, K. 2014. An ecological framework of place: Situating environmental gerontology within a life course perspective. International Journal of Aging and Human Development 79 (3): 183-209.

Duff, S. 2012. The possibilities in neighbourhoods-Utilizing accessory apartments in existing homes to address social, environmental, and economic issues. Urban Design International 17 (1): 33-44.

Durrett, Charles. 2009. Senior Cohousing: A Community Approach to Independent Living - The Handbook, 2nd ed. Gabriola Island, BC: New Society Press.

Forsyth, A. 1992. Changing Places: Case Studies of Innovations in Housing for Older People. Canberra: Australian Government Publishing Service.

Forsyth, A. 2014. Global suburbia and the transition century: Physical suburbs in the long term. Urban Design International 19 (4): $259-273$.

Forsyth, A., E. Salomon, and L. Smead. 2017. Creating Healthy Neighborhoods: Evidence-based Planning and Design Strategies. Chicago: APA Planners Press.

Fried, L.P. 2016. Interventions for human frailty: physical activity as a model. Cold Spring Harbor Perspectives in Medicine 6: a025916.

Frye, A. 2014. Growing old in the city. Journal of Urban Design 19 (3): 269-274.

Gobtop, S.M., and J.A. Memken. 2005. Housing the elderly: investigating solutions to help seniors age in place. Housing and Society 32 (1): 71-84.

Greenfield, E.A. 2016. Support from neighbors and aging in place: can NORC programs make a difference. The Gerontologist 56 (4): 651-659.

Greenfield, E.A., A.E. Scharlach, A.J, Lehning, J.K. Davitt, and C.L. Graham. 2013. A tale of two community initiatives for promoting aging in place: similarities and differences in the national implementation of NORC programs and Villages. The Gerontologist 53 (6): 928-938.

Hackney. 2016. Holly Street Estate. https://www.hackney.gov.uk/holly -street-estate. Accessed 1 Oct 2018.

Hanson, J. 2001. From 'special needs' to 'lifestyle choices': articulating the demand for 'third age' housing. In Inclusive Housing in an Ageing Society: Innovative Approaches, ed. S.M. Peace and C. Holland. Bristol: The Policy Press.

Harttgen, K., P. Kowal, H. Strulik, S. Chatterji, and S. Vollmer. 2013. Patterns of frailty in older adults: comparing results from higher and lower income countries using the Survey of Health, Ageing and Retirement in Europe (SHARE) and the Study on Global AGEing and Adult Health (SAGE). PLoS ONE 8 (10): e75847.

He, W., D. Goodkind, and P. Kowal. 2016. An Aging World (2015) International Population Reports. Washington, DC: U.S. Census.

Hunter, R.H., K. Sydkes, S.G. Lowman, R. Duncan, W. Satariano, and B. Belza. 2011. Environmental and policy change to support healthy aging. Journal of Aging and Social Policy 23 (4): 354-371. 
Institute for Human Centered Design. 2018. Principles. https:// humancentereddesign.org/inclusive-design/principles. Accessed 1 Oct 2018.

Ivery, J.M., D. Akstein-Kahan, and K.C. Murphy. 2010. NORC Supportive Services model implementation and community capacity. Journal of Gerontological Social Work 53 (1): 21-42.

Jenkens, R.T., N. Sult, D. Lessell, and A.Ortigara Hammer. 2011. Financial implications of the green house model. Seniors Housing and Care Journal 19 (1): 3-22.

Jones, A., C. Tilse, H. Bartlett, and R. Stimson. 2008. Integrated Support and Care for People in Later Life. Positioning Paper No. 108. Melbourne: Australian Housing and Urban Research Institute.

Judd, B., D. Olsberg, J. Quinn, L, Groenhart, and O. Demirbilek. 2010. Dwelling, Land and Neighborhood Use by Older Homeowners. Australian Housing and Urban Research Institute Report no 144. Melbourne: AHURI.

Joint Center for Housing Studies of Harvard University. 2016. Projections and Implications of Housing an Aging Population: Older Households 2015-2035. Cambridge, MA: Joint Center for Housing Studies.

Kasper, J.D., V.A. Freedman, B.C. Spillman, and J.L. Wolff. 2015. The Disproportionate impact of dementia on family and unpaid caregiving to older adults. Health Affairs 34 (10): 1642-1649B.

Krieger, A. 2006. Where and how does urban design happen? Harvard Design Magazine 24: 64-71.

Lafortune, G., G. Balestat, and the Disability Study Expert Group Members. 2007. Trends in Severe Disability among Elderly People: Assessing the Evidence in 12 OECD Countries and the Future Implications. Paris: OECD.

Lang, J. 2005. Urban Design: A Typology of Procedures and Products. Oxford: Architectural Press.

Lawler, K. 2001. Aging in Place: Coordinating Housing and Health Care Provision for America's Growing Elderly Population. Cambridge, MA: Joint Center for Housing Studies of Harvard University. http://www.jchs.harvard.edu/sites/jchs.harvard.edu/ files/lawler_w01-13.pdf. Accessed 1 Oct 2018.

Lawton, M., and L. Nahemow. 1973. Ecology and the aging process. In The Psychology of Adult Development and Aging, ed. C. Eisdorfer and M. Lawton, 619-674. Washington, D.C.: American Psychological Association.

Lawton, M. 1980. Environment and Aging. Albany, NY: Center for the Study of Aging.

Lawton, M. 1982. Competence, environmental press, and the adaptation of older people. In Aging and the Environment, eds. M. Lawton, P. Windley, and T. Byerts, 33-59. New York: Springer.

Lien, L.L., C.D. Steggell, and S. Iwarsson. 2015. Adaptive strategies and person-environment fit among functionally limited older adults aging in place: A mixed methods approach. International Journal of Environmental Research and Public Health 12 (9): 11954-11974.

Mackett, R.L., K. Achuthan, and H. Titheridge. 2008. AMELIA: Making streets more accessible for people with mobility difficulties. Urban Design International 13: 80-89.

Masotti, P.J., R. Frick, A. Johnson-Masotti, and S. Macleod. 2006. Naturally occurring retirement communities: a low-cost approach to facilitating healthy aging. American Journal of Public Health 96 (7): 1164-1170.

McDonough, K.E., and J.K. Davitt. 2011. It takes a village: Community practice, social work, and aging in place. Journal of Gerontological Social Work 54: 528-541.

Mitchell, L., E. Burton, and S. Raman. 2004. Dementia-friendly cities: designing intelligible neighbourhoods for life. Journal of Urban Design 9 (1): 89-101.

New York Academy of Medicine. N.d. Age-friendly NYC. http:// nyam.org/age-friendly-nyc/our-work/. Accessed 1 Oct 2018.

New York State Office for the Aging. N.d. Naturally Occurring Retirement Community Supportive Service Program
(NORC-SSP) and Neighborhood NORC (NNORC) https://aging .ny.gov/NYSOFA/Programs/CommunityBased/NORC-NNORC .cfm. Accessed 1 Oct 2018.

NIA and WHO. 2011. Global Health and Aging. Washington DC: NIA.

OECD. 2015. SF2.5 Childlessness. https://www.oecd.org/els/family/ SF_2-5-Childlessness.pdf. Accessed 1 Oct 2018.

Park, S., B. Kim, and J. Cho. 2017. Formal volunteering among vulnerable older adults from an environmental perspective: Does senior housing matter. Journal of Housing for the Elderly 31 (4): 334-350

Plouffe, L., and A. Kalache. 2010. Towards global age-friendly cities: determining urban features that promote active aging. Journal of Urban Health 87 (5): 733-739.

Prioux, F., M. Mazuy, and M. Barbieri. 2010. Recent demographic developments in France: Fewer adults live with a partner. Population-E 65 (3): 363-414.

Rowe, J.W. and R.L. Kahn. 1998. Successful Aging. New York: Pantheon Books.

Rowe, P., A. Forsyth, and H.Y. Kan. 2016. China's Urban Communities: Concepts, Contexts, and Well-being. Berlin: Birkhäuser.

Roy, N., R. Dube, C. Despres, A. Freitas, and F. Legare. 2018. Choosing between staying at home or moving: A systematic review of factors influencing housing decisions among frail older adults. PLoS ONE 13 (1): e0189266. https://doi. org/10.1371/journal.pone.0189266. Accessed 1 Oct 2018.

RTI International and Leadingage. 2016. Support and Services at Home (SASH) Evaluation: Second Annual Report. https://aspe. hhs.gov/basic-report/support-and-services-home-sash-evalu ation-second-annual-report. Accessed 1 Oct 2018.

Straits Times. 2017. Singapore's first 'retirement kampung' stirs to life as residents move in. October 16: https://www.straitstim es.com/singapore/housing/kampung-admiralty-stirs-to-life-asresidents-move-in. Accessed 1 Oct 2018.

Sharkey, S., S. Hudak, S.D. Horn, B. James, M. Stat, and J. Howes. 2011. Frontline caregiver daily practices: a comparison study of traditional nursing homes and the Green House project sites. Journal of the American Geriatrics Society 59: 126-132.

U.S. National Cancer Institute. N.d. NCI Dictionary of Cancer Terms. https://www.cancer.gov/publications/dictionaries/cance r-terms. Accessed 1 Oct 2018.

Wahl, H.W., S. Iwarsson, and F. Oswald. 2012. Aging well and the environment: toward an integrative model and research agenda for the future. The Gerontologist 52 (3): 306-316.

Wang, W., and K. Parker. 2014. Record Share of Americans Have Never Married: As Values, Economics and Gender Patterns Change. Washington, D.C.: Pew Research Center.

Wardrip, K. 2010. Cohousing for Older Adults. Washington, DC: AARP Public Policy Institute.

West, L.A., S. Cole, D. Goodkind, and W. He. (2014) $65+$ in the United States: (2010). Current Population reports. Washington DC: U.S. Census Bureau.

World Health Organization n.d. Life Expectancy. http://www.who. int/gho/mortality_burden_disease/life_tables/situation_trend s_text/en/. Accessed 1 Oct 2018.

World Health Organization. 2002. Active ageing: A policy framework. http://apps.who.int/iris/bitstream/handle/10665/67215 /WHO_NMH_NPH_02.8.pdf?sequence=1. Accessed 1 Oct 2018.

World Health Organization. 2007. Checklist of Essential Features of Age-Friendly Cities. WHO Resource, http://www.who.int/agein g/publications/Age_friendly_cities_checklist.pdf. Accessed 1 Oct 2018

Publisher's Note Springer Nature remains neutral with regard to jurisdictional claims in published maps and institutional affiliations. 